Revta brasil. Bot., São Paulo, V.23, n.4, p.385-393, dez. 2000

\title{
Flúor em chuva simulada: sintomatologia e efeitos sobre a estrutura foliar e o crescimento de plantas arbóreas ${ }^{1}$
}

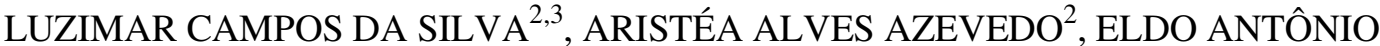 MONTEIRO DA SILVA ${ }^{2}$ e MARCO ANTONIO OLIVA ${ }^{2}$}

(recebido em 20 de outubro de 1999; aceito em 25 de maio de 2000)

\begin{abstract}
Fluoride in simulated rain: symptomatology and effects on leaf structure and growth of wood plants). The objectives of this study was to characterize the effects of fluoride on seedlings and young plants of native woody species from Parque Estadual do Rio Doce (MG) and on the leaf blade structure of the most sensitive of the studied tree species. This work was carried out to gain information on diagnosing criteria for bioindication and to throw some light on the mechanisms of plant resistance and tolerance in order to assist in the revegetation programs of highly affected areas. The employed species were Gallesia gorazema Moq. (Phytolaccaceae), Genipa americana L. (Rubiaceae), Joannesia princeps Vell. (Euphorbiaceae), Peltophorum dubium (Spreng.) Taub. (Leguminosae, Caesalpinioideae) and Spondias dulcis Forst. f. (Anarcadiaceae). Seedlings and young plants of those species were submitted to rain with dissolved fluoride ( $30 \mathrm{mg} . \mathrm{L}^{-1}$ ), during $20 \mathrm{~min}$ daily, for 10 consecutive days. Apical and marginal necrosis occurred in the leaf blades of all species just after the first simulated rain. Two days after treatment, S. dulcis, in the young plant stage, showed to be the most sensitive species by exhibiting large necrotic areas, while G. americana was the most resistant species. At the young plant stage, the species that accumulated more fluoride were also the most sensitive ones; such a relation was not observed in plants at the seedling stage. The pollutant at the level employed caused drastic alterations in the leaf blade of $S$. dulcis and also damaged all of its anatomical structure. The high susceptibility of $S$. dulcis to fluoride suggests that this species possess potential features to be employed as a bioindicator. However, for a better characterization of the responses of $S$. dulcis to fluoride and its usage in biomonitoring programs, more studies are required.
\end{abstract}

RESUMO - (Flúor em chuva simulada: sintomatologia e efeitos sobre a estrutura foliar e o crescimento de plantas arbóreas). Os objetivos deste trabalho foram: caracterizar os efeitos do flúor em espécies arbóreas nativas, nos estádios de plântula e muda; identificar injúrias provocadas pelo flúor na estrutura da lâmina foliar da espécie mais sensível; fornecer subsídios para seleção de características a serem utilizadas na bioindicação; e contribuir com informações sobre a resistência ou tolerância das plantas, visando ao reflorestamento de áreas impactadas pela chuva com flúor. As espécies analisadas foram Gallesia gorazema Moq. (Phytolaccaceae), Genipa americana L. (Rubiaceae), Joannesia princeps Vell. (Euphorbiaceae), Peltophorum dubium (Spreng.) Taub. (Leguminosae, Caesalpinioideae) e Spondias dulcis Forst. f. (Anacardiaceae). Plântulas e mudas dessas espécies, provenientes do Parque Estadual do Rio Doce (MG), foram submetidas a $20 \mathrm{~min}$ diários de chuva com flúor $\left(30 \mathrm{mg} \cdot \mathrm{L}^{-1}\right)$, por 10 dias consecutivos. Necroses apicais e marginais foram observadas em todas as espécies analisadas, logo após a primeira chuva simulada. $S$. dulcis, no estádio de muda, foi a espécie mais sensível ao flúor, pois apresentou extensas necroses com apenas dois dias de tratamento, enquanto que G. americana foi a espécie mais resistente. Nas mudas, as espécies que acumularam mais flúor foram também as que apresentaram maior sensibilidade a esse poluente; essa relação não foi verificada nas plântulas. A concentração de flúor utilizada promoveu alterações drásticas na lâmina foliar de $S$. dulcis com extensas áreas necrosadas, danificando toda a sua estrutura anatômica. A sensibilidade ao flúor observada em $S$. dulcis indica que essa espécie apresenta potencial para ser usada como bioindicadora. Entretanto, estudos detalhados serão necessários para a melhor caracterização das respostas de S. dulcis ao flúor visando a sua utilização em programas de biomonitoramento ambiental.

Key words - Fluoride, bioindicators, native plants, symptomatology

\section{Introdução}

A problemática da poluição ambiental, antes mais restrita a países industrializados, tem hoje um caráter universal. No Brasil, cidades como São Paulo, Cubatão, Volta Redonda e Rio de Janeiro con-

1. Parte da dissertação de mestrado de L.C. da Silva.

2. Departamento de Biologia Vegetal, Universidade Federal de Viçosa, Av. PH Rolfs, s/n, 36.571-000 Viçosa, MG, Brasil.

3. Autor para correspondência: luzimar@alunos.ufv.br vivem com esse fato (Alves \& Oliva 1993). Em São Paulo, estudos realizados em Cubatão têm mostrado os muitos danos à vegetação da Serra do Mar causados por poluentes atmosféricos (Klumpp et al. 1994, Klumpp et al. 1996b, Domingos et al. 1998) e, na Reserva Biológica do Instituto de Botânica, os níveis de particulados atmosféricos são comparáveis aos de outros países comprovadamente poluídos (Vuono et al. 1984).

O flúor encontrado na atmosfera, principalmente sob a forma de ácido fluorídrico (HF), apresenta grande fitotoxicidade para a vegetação. Sua concentração na precipitação atmosférica varia de 1 a 
$1.000 \mu \mathrm{g} . \mathrm{L}^{-1}$, podendo chegar a $10 \mathrm{mg} . \mathrm{L}^{-1} \mathrm{em}$ áreas industriais (Smith \& Hodge 1979). Os sintomas do flúor nas plantas incluem cloroses, necroses, redução no crescimento e remoção da cera epicuticular, entre outros (Prado Filho 1993, Oliva et al. 1997).

As plantas diferem em sua sensibilidade aos poluentes atmosféricos, podendo ser usadas como bioindicadoras da qualidade do ar. Algumas espécies são particularmente susceptíveis à poluição (bioindicadores de reação), enquanto outras podem acumular os poluentes em altas concentrações sem que sintomas visíveis sejam observados (bioindicadores de acumulação) (Mudd \& Kozlowski 1975, Kozlowski 1980, Arndt et al. 1995). Os bioindicadores podem ser passivos, quando estão presentes em seu ambiente natural, ou ativos, quando são introduzidos, de forma padronizada, na área de estudo (Ellenberg et al. 1991).

Segundo Strehl \& Arndt (1989), a bioindicação é um método eficiente e de baixo custo, que deve ser adequado às condições de cada país. Nas regiões tropicais, ainda são poucos os trabalhos sobre biomonitoramento da poluição utilizando espécies vegetais e no Brasil existem algumas iniciativas neste sentido (Klumpp et al. 1995, Klumpp et al. 1996a, Klumpp et al. 1996b, Domingos et al. 1998). Entretanto, para fundamentar possíveis programas de biomonitoramento, ainda são necessárias pesquisas para avaliação das alterações morfológicas, fisiológicas, anatômicas e bioquímicas, entre outras, ocasionadas por poluentes liberados na atmosfera, e para esclarecimento dos possíveis mecanismos de resistência ou susceptibilidade em diferentes espécies de plantas (Kozlowski 1980).

O Parque Estadual do Rio Doce (PERD) compreende uma área de 35.974 ha, sendo a maior área de floresta tropical de Minas Gerais sob proteção legal (IEF 1994). Localizado na região do Vale do Aço, ao leste do Estado de Minas Gerais, o Parque abrange parte dos municípios de Marliéria, Dionísio e Timóteo e apresenta, na região norte, usinas siderúrgicas de grande porte, como ACESITA, USIMINAS e USIMEC, e reflorestamentos com eucalipto para produção de carvão, fonte energética para essas usinas. Estudos preliminares na região industrial do vale do rio Doce indicaram que as precipitações eram de natureza ácida e apresentavam potencial para causar efeitos deletérios ao ecossistema (Castro et al.
1987). Apesar de não existirem dados sobre a concentração de flúor na região, as siderúrgicas e as usinas alimentadas a carvão estão incluídas entre as principais fontes de poluição, aumentando, consideravelmente, os índices do flúor na atmosfera (Dobbs 1974).

Por sua localização em uma região sujeita a forte pressão antrópica, pela necessidade de preservação dessa importante área florestal do Estado de Minas Gerais e em face da vegetação da região norte do Parque já apresentar sinais evidentes de injúria, provavelmente relacionados ao impacto da poluição, o presente trabalho foi desenvolvido com o propósito de fornecer informações básicas sobre respostas de espécies arbóreas do PERD a poluentes.

Os objetivos deste trabalho foram avaliar os efeitos do flúor, dissolvido na chuva, em espécies arbóreas nos estádios de plântula e muda; identificar as injúrias provocadas pela chuva contendo flúor na estrutura foliar da espécie arbórea nativa mais sensível a esse poluente; fornecer subsídios para a seleção de características a serem utilizadas na bioindicação; e contribuir com informações sobre a resistência ou tolerância das plantas, visando ao reflorestamento de áreas cuja vegetação foi afetada pela ação do flúor.

\section{Material e métodos}

As espécies vegetais estudadas foram Gallesia gorazema Moq. (Phytolaccaceae - pau d'alho), Genipa americana L. (Rubiaceae - jenipapo), Joannesia princeps Vell. (Euphorbiaceae cotieira), Peltophorum dubium (Spreng.) Taub. (Leguminosae, Caesalpinioideae - angico canjiquinha), e Spondias dulcis Forst. f. (Anacardiaceae - cajá-mirim) e foram selecionadas por apresentarem crescimento rápido, essencial para a caracterização das respostas aos tratamentos. As plântulas e mudas, fornecidas pelo viveiro do Parque Estadual do Rio Doce (MG), foram obtidas mediante a germinação de sementes coletadas no próprio PERD.

Os experimentos foram conduzidos no laboratório de Fisiologia Vegetal da Universidade Federal de Viçosa (UFV), localizado na cidade de Viçosa. O clima na região de Viçosa é do tipo tropical de altitude (Cwb da classificação de Köppen), com verões brandos e temperatura média do mês mais quente inferior a $22{ }^{\circ} \mathrm{C}$ (Köppen 1948).

As plântulas, com cerca de dois meses de idade, portando cotilédones e dois nós com folhas, foram fornecidas em tubetes e as mudas, com aproximadamente quatro meses de idade, em sacos plásticos. As mudas foram transferidas para vasos plásticos de dois litros, preenchidos com areia e as plântulas permaneceram em tubetes. Todas as plantas ficaram de 15 a 20 dias em área coberta, para aclimatação, e receberam solução nutritiva de Hoagland (um quarto de força) a cada cinco dias, até saturação do 
solo, durante o período de aclimatação e até o término do tratamento com flúor.

As plântulas e mudas foram submetidas a 20 min diários de chuva com flúor, por 10 dias consecutivos. A chuva simulada foi aplicada utilizando-se uma câmara construída a partir do modelo proposto por Evans et al. (1977) e adaptada por Alves et al. (1990). No tratamento controle, foi aplicada chuva apenas com água destilada. A chuva com flúor foi preparada utilizando-se $30 \mathrm{mg}$ de flúor, na forma de fluoreto de potássio, para cada litro de água destilada (30 mg. $\left.\mathrm{L}^{-1}\right)$. Tendo em vista a natureza cumulativa da toxidez por flúor, foi utilizada uma concentração elevada desse poluente com o objetivo de se avaliarem as diferenças de respostas das espécies, num curto espaço de tempo (Bustamante et al. 1993).

Antes e depois de cada chuva, as plantas ficaram expostas sob um painel luminoso, sob densidade de fluxo radiante de $95 \mathrm{~W} . \mathrm{m}^{-2}$, por $15 \mathrm{~min}$, e no restante do dia ficavam em ambiente aberto, sob condições não controladas. O delineamento experimental foi o inteiramente casualizado, com cinco repetições por tratamento.

Diariamente, durante os 10 dias de tratamento, foram feitas observações e registros, sob a forma de esquemas, do aparecimento e localização das injúrias relacionadas à ação do flúor. $\mathrm{Na}$ análise visual, foram considerados o número e o tamanho das manchas necróticas e cloróticas em relação ao tamanho da folha, utilizando a seguinte escala: levemente injuriada (com manchas necróticas e cloróticas esparsas), moderadamente injuriada (com 30 a $50 \%$ da área foliar necrosada), muito injuriada (com 50 a 70\% da área foliar necrosada) e extremamente injuriada (com mais de $70 \%$ da área foliar necrosada). Os sintomas (clorose e necrose) foram descritos e documentados fotograficamente.

Para a determinação das concentrações de flúor, foram coletadas folhas inteiras (jovem, em expansão e adulta), de cinco plantas, 24 h após a última chuva, exceto para $S$. dulcis e $G$. gorazema, coletadas após a segunda e quarta chuvas, respectivamente. As amostras foram previamente secas em estufa, a $70{ }^{\circ} \mathrm{C}$, até se obter peso constante, sendo, em seguida, pesadas, moídas e as cinco repetições foram reunidas em uma amostra composta por espécie. A determinação potenciométrica do teor de flúor, com eletrodo específico, foi realizada após extração com ácido perclórico 0,1 M (Garcia-Ciudad et al. 1985), utilizando-se o ajustador de força iônica proposto por Larsen \& Widdowson (1971). Para efeito de comparação, fez-se uma estimativa da taxa de acumulação diária de flúor (concentração total de flúor/número de chuvas simuladas) em cada espécie.

A altura da planta foi medida antes da primeira chuva e $24 \mathrm{~h}$ após o término do tratamento, em cinco repetições por espécie. Os resultados foram submetidos à análise de variância e teste de Tukey, a 5\%, para comparação das médias.

No presente experimento, o número e a extensão dos sintomas presentes, após o tratamento com flúor, foram utilizados como critérios para definir a espécie mais sensível e a mais resistente ao flúor.

Para a caracterização anatômica da injúria por flúor, foram coletadas amostras de folhas (jovens, em expansão e adultas) das cinco plantas da espécie mais sensível. Após fixação em CRAFT III (Berlyn \& Miksche 1976) e desidratação em série etílica/butílica, as amostras foram incluídas em parafina. Cortes transversais, com $10 \mu \mathrm{m}$ de espessura, foram corados em azul de astra e fucsina, após tratamento com ácido tânico e cloreto férrico, para evidenciação da parede celulósica. As lâminas foram montadas em permount. Após observação, fez-se documentação fotográfica, utilizando-se um microscópio fotônico (ZEISS-DOCUVAL).

\section{Resultados}

Sintomatologia em mudas - Após o primeiro dia de chuva com flúor, pelo menos um indivíduo de $J$. princeps, G. americana e $P$. dubium, no estádio de muda, apresentou sintomas visíveis de injúria, enquanto todos os indivíduos de $S$. dulcis já evidenciavam necroses. Em G. gorazema, os primeiros sintomas ocorreram após a segunda chuva.

Entre as espécies analisadas, as mudas de $S$. dulcis foram as mais sensíveis à chuva contendo flúor, mostrando necroses extensas (figura 1), desde o primeiro dia de tratamento; as necroses atingiram mais de $70 \%$ da área foliar no segundo dia do experimento, época em que foi coletado o material para análise. Nessa espécie, as folhas das mudas apresentaram a maior taxa de acumulação diária de flúor (figura 2), tanto no tratamento com flúor quanto no controle, apresentando a folha em expansão maior grau de injúria do que a folha jovem. No controle, o crescimento diário das mudas de $S$. dulcis foi maior que o de todas as outras espécies (figura 3); entretanto, não foi possível se obter os dados referentes ao efeito do flúor no crescimento pois o ápice das plantas apresentava-se retorcido, impossibilitando as medições.

A segunda espécie mais sensível, no estádio de muda, foi G. gorazema, que mostrou muitas necroses, cloroses e intensa abscisão foliar, sendo a coleta do material vegetal para a quantificação de flúor realizada após a quarta chuva. Essa espécie
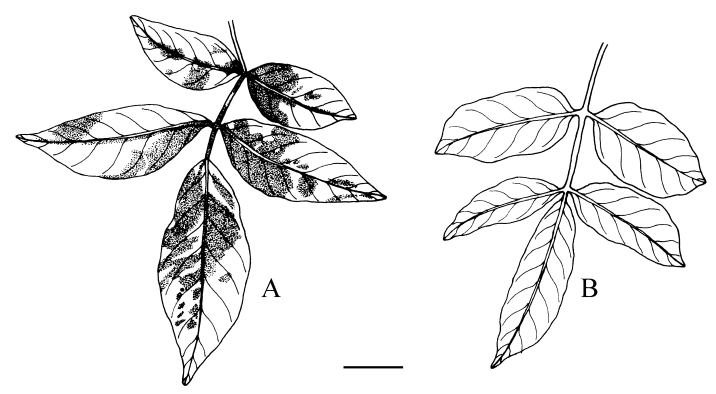

Figura 1. Folhas de mudas de Spondias dulcis. A. Necroses extensas (hachurado), após dois dias de tratamento com flúor; B. Controle. Barra $=12 \mathrm{~mm}$. 

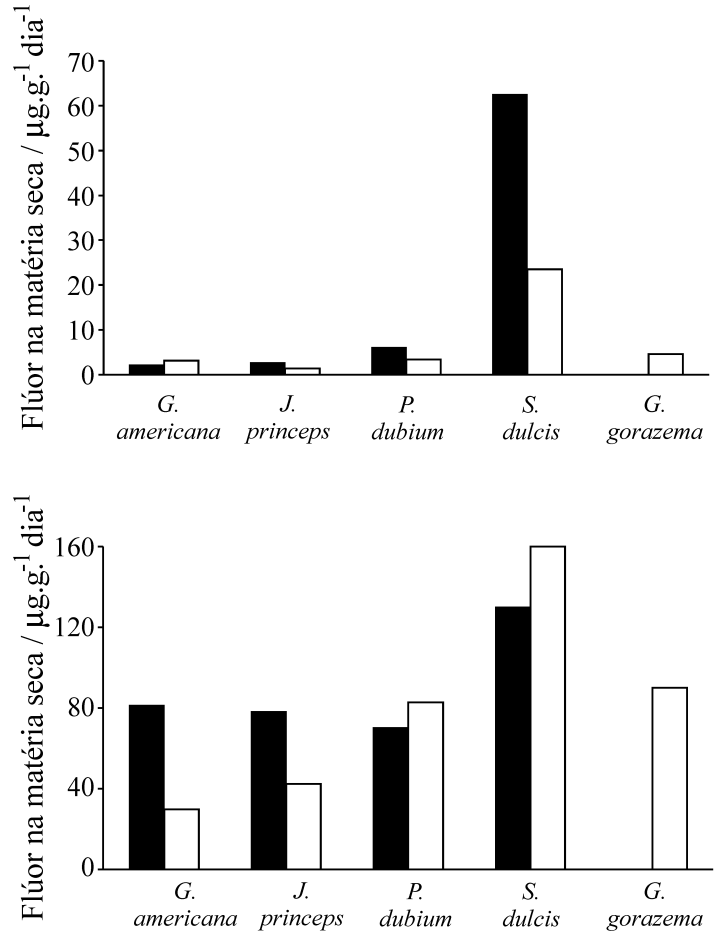

Figura 2. Taxa de acumulação de flúor na matéria seca, $\mu \mathrm{g} \cdot \mathrm{g}^{-1} \cdot \mathrm{dia}^{-1}$, em mudas $(\square$ ) e plântulas $(\square)$ de Genipa americana, Joannesia princeps, Peltophorum dubium, Spondias dulcis e Gallesia gorazema submetidas à chuva simulada. $\mathrm{A}=$ controle; $\mathrm{B}=$ chuva com flúor $\left(30 \mathrm{mg} \cdot \mathrm{L}^{-1}\right)$.

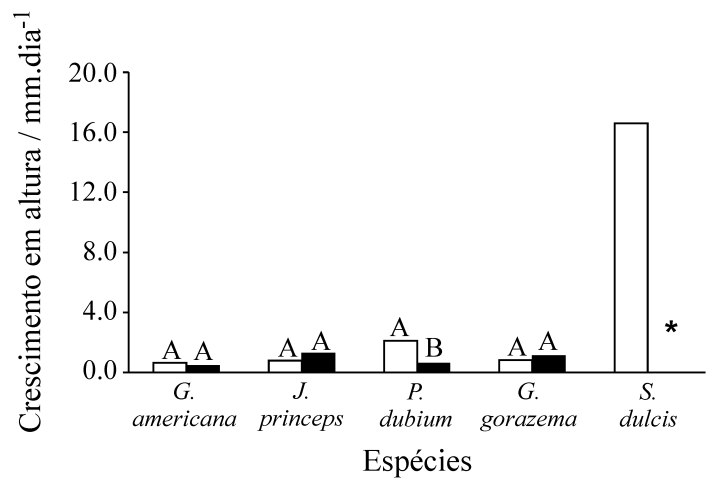

Figura 3. Crescimento diário, em altura, das mudas de Genipa americana, Joannesia princeps, Peltophorum dubium e Gallesia gorazema submetidas à chuva simulada. Controle $(\square)$; Tratamento com $30 \mathrm{mg} . \mathrm{L}^{-1}$ de flúor $(\square$. Médias indicadas por letras iguais não diferem entre si, pelo teste de Duncan, a 5\% de probabilidade.

* Material vegetal não medido devido ao aspecto retorcido que apresentava após a segunda chuva simulada. acumulou, em média, $90 \mu \mathrm{g} \cdot$ dia $^{-1}$ de flúor na matéria seca (figura 2), a segunda maior taxa de acúmulo desse poluente entre as espécies analisadas. As folhas jovens de G. gorazema começaram a manifestar os primeiros sintomas antes que a folha em expansão, mas esta apresentou maior intensidade de sintomas no final do experimento.

As mudas de J. princeps e $P$. dubium apresentaram respostas similares, com moderadas injúrias nas folhas jovens e leves injúrias nas folhas em expansão. Entretanto, o acúmulo diário de flúor em mudas de $P$. dubium foi maior do que em J. princeps (figura 2) e, ao final do experimento, a concentração de flúor nos tecidos foliares de $P$. dubium foi de 827,5 $\mu \mathrm{g} . \mathrm{g}^{-1}$, enquanto em $J$. princeps foi de $423,3 \mu \mathrm{g} \cdot \mathrm{g}^{-1}$ (tabela 1 ). As folhas de $J$. princeps apresentaram os primeiros sintomas no primeiro e segundo dias; as folhas jovens de $P$. dubium apresentaram os primeiros sintomas entre o terceiro e o quinto dias, e a folha em expansão, entre o primeiro e o quarto dias.

As mudas de G. americana foram as mais resistentes ao tratamento, respondendo com poucas manchas necróticas e cloróticas, ficando levemente injuriadas, embora tenham tido os primeiros sintomas manifestados da primeira à terceira chuva. Acrescentase, ainda, o fato dessa espécie ter apresentado a menor taxa de acumulação diária de flúor nas folhas e a menor concentração final de flúor nos tecidos foliares, em relação às espécies analisadas (figura 2, tabela 1).

Das espécies coletadas após 10 dias de tratamento com flúor ( $G$. americana, $J$. princeps e $P$. dubium), a que apresentou o maior acúmulo de flúor foi $P$. dubium (figura 2, tabela 1), a única espécie cujo crescimento em altura das mudas foi reduzido (figura 3, tabela 2).

Sintomatologia em plântulas - As plântulas de $J$. princeps foram as mais afetadas pelo tratamento; os sintomas começaram a surgir logo após a primeira chuva, ficando as folhas mais injuriadas do que as das demais espécies. Entretanto, J. princeps não foi a espécie que apresentou a maior taxa de acúmulo diário de flúor (figura 2).

A segunda espécie mais sensível foi $S$. dulcis, que teve a folha em expansão da plântula mais afetada pela chuva com flúor do que a folha jovem e, entre as espécies analisadas, foi a que apresentou maior taxa de acúmulo diário de flúor (figura 2). No controle, apesar de a taxa de acúmulo de flúor tam- 
Tabela 1. Concentrações de flúor, $\mu \mathrm{g} \cdot \mathrm{g}^{-1}$ de matéria seca, em plântulas e mudas de Genipa americana, Joannesia princeps, Peltophorum dubium, Spondias dulcis e Gallesia gorazema, submetidas a $20 \mathrm{~min}$ diários de chuva contendo flúor $\left(30 \mathrm{mg} . \mathrm{L}^{-1}\right)$, durante 10 dias consecutivos.

\begin{tabular}{lccccc}
\hline Espécie & \multicolumn{2}{c}{ Plântula } & & \multicolumn{2}{c}{ Muda } \\
\cline { 2 - 3 } \cline { 5 - 6 } & Controle & Chuva com flúor & & Controle & Chuva com flúor \\
\hline Genipa americana & 21,5 & 812,5 & & 31,0 & 298,3 \\
Joannesia princeps & 26,5 & 781,6 & & 14,0 & 423,3 \\
Peltophorum dubium & 61,0 & 702,5 & & 33,5 & 827,5 \\
Spondias dulcis & $125,0^{*}$ & $260,0^{*}$ & & $47,0^{*}$ & $320,0^{*}$ \\
Gallesia gorazema & - & - & & $18,5^{* *}$ & $360,0^{* *}$ \\
\hline
\end{tabular}

* Material coletado após dois dias de tratamento. ** Material coletado após quatro dias de tratamento.

bém ter sido elevada, não foram observados sintomas de injúria por flúor nas plântulas que apresentaram maior quantidade de flúor do que as mudas (tabela 1).

As plântulas de G. americana e P. dubium apresentaram injúrias leves, com os sintomas sendo observados primeiramente em G. americana. Entretanto, durante o experimento, desenvolveram-se novas folhas nas plântulas de $P$. dubium, que foram mais afetadas que as folhas iniciais, apresentando injúrias moderadas. As plântulas de G. americana acumularam, em média, 81,3 $\mu$ g.dia ${ }^{-1}$ de flúor na matéria seca enquanto que as de $P$. dubium acumularam 70,3 $\mu$ g.dia ${ }^{-1}$ (figura 2).

O tratamento com flúor não influenciou o crescimento em altura das plântulas de nenhuma das espécies vegetais avaliadas neste experimento (tabela 2 ).

Em resposta à chuva contendo fluoreto, a taxa de acumulação diária de flúor nas plântulas de $G$. americana e $J$. princeps foi maior que nas mudas, ocorrendo o inverso em $P$. dubium e $S$. dulcis (figura 2).
De modo geral, G. americana e $P$. dubium apresentaram maior resistência à chuva com flúor, tanto no estádio de plântula quanto no de muda. Em J. princeps, as plântulas foram mais sensíveis do que as mudas e, em $S$. dulcis, foi verificado o contrário. Em G. gorazema, não havia disponibilidade do material vegetal no estádio de plântula para se comparar com a grande sensibilidade das mudas ao tratamento com flúor.

Alterações na estrutura da lâmina foliar de Spondias dulcis - A folha de S. dulcis é dorsiventral e hipoestomática, apresentando epiderme adaxial e abaxial unisseriada. O mesofilo é formado por uma camada de parênquima paliçádico e quatro a cinco camadas de parênquima lacunoso (figura 4). Na nervura mediana, ocorre uma ilhota de colênquima subjacente à epiderme adaxial e uma camada contínua de colênquima em contato com a epiderme abaxial; observa-se a presença de canais secretores, podendo variar de dois a quatro, sendo que um deles está localizado próximo à epiderme adaxial e de um a três voltados para a face abaxial;

Tabela 2. Taxa de crescimento diário, em altura $(\mathrm{cm})$, das plântulas e mudas de Genipa americana, Joannesia princeps, Peltophorum dubium e Gallesia gorazema, submetidas a 20 min diários de chuva contendo flúor (30 mg. $\left.\mathrm{L}^{-1}\right)$, durante 10 dias consecutivos.

\begin{tabular}{lccccc}
\hline \multirow{2}{*}{ Espécie } & \multicolumn{2}{c}{ Plântula } & & \multicolumn{2}{c}{ Muda } \\
\cline { 2 - 3 } \cline { 5 - 6 } & Controle & Chuva com flúor & & Controle & Chuva com flúor \\
\hline Genipa americana & $0,06 \mathrm{Ba} \pm 0,02$ & $0,07 \mathrm{Aa} \pm 0,01$ & & $0,06 \mathrm{Aa} \pm 0,02$ & \\
Joannesia princeps & $0,07 \mathrm{ABa} \pm 0,02$ & $0,08 \mathrm{Aa} \pm 0,03$ & & $0,08 \mathrm{Aa} \pm 0,02$ & \\
Peltophorum dubium & $0,16 \mathrm{Aa} \pm 0,04$ & $0,14 \mathrm{Aa} \pm 0,03$ & & $0,21 \mathrm{Aa} \pm 0,04$ & $0,13 \mathrm{Aa} \pm 0,05$ \\
Gallesia gorazema & - & - & & $0,08 \mathrm{Aa} \pm 0,03$ & $0,06 \mathrm{Ab} \pm 0,02$ \\
\hline
\end{tabular}

Médias seguidas por letras maiúsculas iguais na vertical e por letras minúsculas iguais, na horizontal, não diferem entre si pelo teste de Tukey, a 5\% de probabilidade. 
as células do parênquima apresentam, algumas vezes, principalmente próximo aos tecidos vasculares, conteúdos fenólicos (figura 5). $\mathrm{Na}$ margem da folha, existe um canal secretor, situado na parte abaxial do feixe vascular (figura 6).
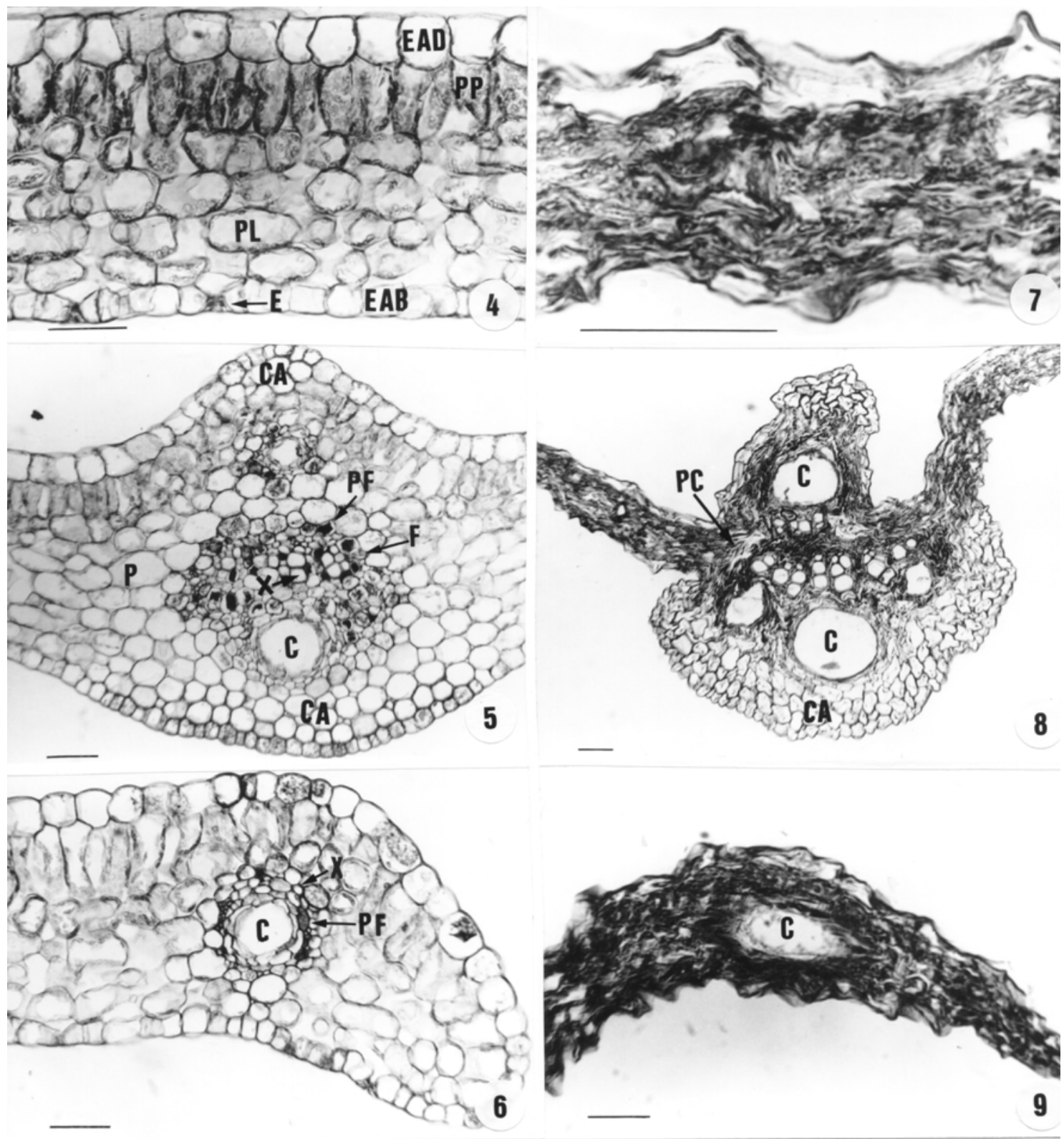

Figuras 4-9. Cortes transversais da lâmina foliar de mudas de Spondias dulcis. 4-6. Tratamento controle. 7-9. Efeitos do flúor. 4. Epiderme adaxial (EAD) e abaxial (EAB) unisseriada, estômatos (E), parênquima paliçádico (PP) e parênquima lacunoso (PL). 5. Nervura mediana mostrando xilema $(\mathrm{X})$, floema $(\mathrm{F})$, colênquima angular $(\mathrm{CA})$, parênquima $(\mathrm{P})$ com compostos fenólicos $(\mathrm{PF})$ e canais secretores $(\mathrm{C}) .6$. Margem com mesofilo indiferenciado mostrando canal secretor $(\mathrm{C})$, algumas células xilemáticas $(\mathrm{X})$ e parênquima em torno do canal secretor contendo compostos fenólicos (PF). 7. Necrose da lâmina foliar com plasmólise das epidermes e colapso do mesofilo. 8. Nervura mediana com células do parênquima colapsadas (PC) e células do colênquima plasmolisadas (CA). 9. Necrose marginal com colapso total dos tecidos. Barra $=40 \mu \mathrm{m}$. 
A concentração de flúor usada no presente experimento promoveu alterações drásticas na lâmina foliar de S. dulcis, com áreas necrosadas generalizadas, tanto nas plântulas como nas mudas. Em necroses intervenais, ocorreram plasmólise da epiderme adaxial e colapso do parênquima paliçádico, do parênquima lacunoso e da epiderme abaxial, permanecendo nítidas, algumas vezes, as regiões estomáticas (figura 7).

Na nervura mediana, pode-se observar que a necrose atinge, em maior ou menor grau, quase todos os tecidos, verificando-se plasmólise das células na região abaxial e colapso total das células na região adaxial da nervura, permanecendo aparentemente intactos apenas os elementos xilemáticos (figura 8).

Nas margens necrosadas, pode-se observar colapso total das epidermes e dos outros tecidos, visualizando-se os canais secretores que apresentam maior diâmetro, quando comparados com o controle (figura 9).

Nas regiões de transição entre a área necrosada e o tecido sadio, houve redução na espessura da lâmina foliar provocada pela necrose e plasmólise generalizada das células do mesofilo (figuras $10 \mathrm{e}$ 11). Em algumas regiões da folha foi verificado um enrugamento da lâmina, em decorrência de necroses marginais e apicais simultâneas (figura 12).

\section{Discussão}

A poluição exerce um efeito global sobre a vegetação, uma vez que a diferença de sensibilidade à poluentes pode afetar a competição natural entre as espécies arbóreas de um determinado ecossistema. Assim, o crescimento de uma espécie pode ser estimulado em função do efeito inibidor da poluição sobre outra espécie (Kozlowski \& Pallardy 1997), podendo dar espaço às espécies oportunistas, que acabam descaracterizando a vegetação original (Murray 1981).

A folha é o órgão mais sujeito a ação dos poluentes atmosféricos. Em conseqüência, vários parâmetros foliares podem ser utilizados para qualificar e quantificar a influência desses poluentes sobre as plantas, tais como: lesões foliares, percentagem de folhas injuriadas, área foliar necrosada, crescimento, taxa de fotossíntese e respiração, conteúdo de clorofila e acúmulo de poluentes no tecido foliar (Prado

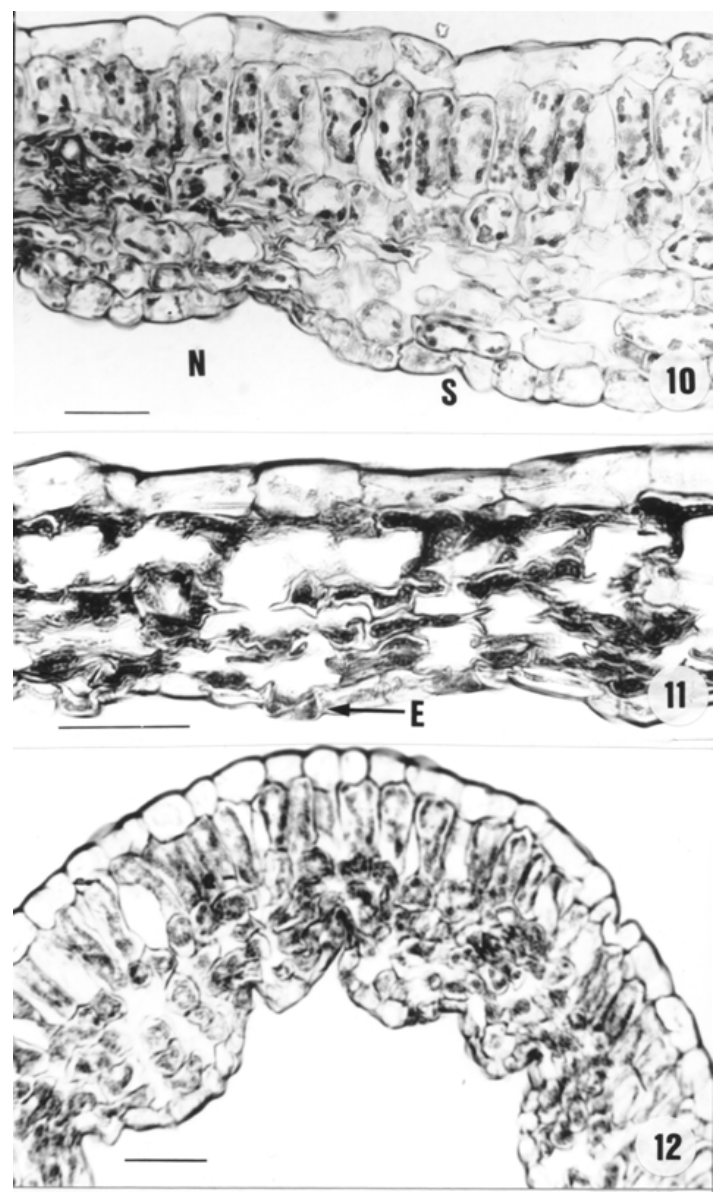

Figuras 10-12. Cortes transversais da lâmina foliar de mudas de Spondias dulcis, expostas à chuva contendo flúor. 10. Região de transição entre as áreas sadia $(\mathrm{S})$ e necrosada $(\mathrm{N})$, observando-se, nesta última, redução na espessura do mesofilo. 11. Plasmólise acentuada dos tecidos observando-se estômato deformado (E). 12. Aspecto encarquilhado da lâmina foliar com a formação de protuberâncias e depressões na epiderme abaxial. Barra $=40 \mu \mathrm{m}$.

Filho 1993). O grau de injúria foliar tem tido grande aceitação quando se avalia a resistência a poluentes, em diferentes espécies vegetais (Kozlowski \& Pallardy 1997), razão pela qual foi adotado como critério, no presente trabalho, para se avaliar a sensibilidade das espécies ao tratamento de chuva simulada contendo fluoreto.

Os níveis de flúor nas folhas considerados normais em ambientes não poluídos situam-se entre 15 a $20 \mu \mathrm{g} . \mathrm{g}^{-1}$ na matéria seca (Weinstein 1977, Miller 1993). Entretanto, algumas espécies podem acumular flúor mesmo crescendo em áreas não poluídas ou 
solos não contaminados (Davison 1983, Klumpp et al. 1996b), como verificado na maioria das espécies estudadas, tanto no estádio de muda quanto no de plântula.

Dentre as espécies analisadas, $S$. dulcis foi a mais sensível à chuva com flúor. As mudas evidenciaram folhas em expansão com extensas necroses, que atingiram quase toda a lâmina foliar, além de alta taxa de acumulação diária de flúor, verificada também no tratamento controle. S. dulcis apresenta um crescimento muito rápido o que pode justificar, em parte, a alta sensibilidade à chuva com flúor. Os dados obtidos sugerem algum tipo de relação entre a capacidade de acumulação diária de flúor com o ritmo de crescimento das mudas, pois a espécie de maior crescimento diário, $S$. dulcis, foi a que apresentou maior acumulação diária de flúor.

À semelhança do que já foi observado para outras espécies, em resposta ao flúor (Treshow \& Anderson 1991, Klumpp et al. 1995), nas mudas de S. dulcis, G. gorazema e G. americana, houve relação entre o grau de injúria e o conteúdo de flúor das folhas: S. dulcis e G. gorazema foram as espécies com maior taxa de acumulação diária de flúor e maior grau de injúria enquanto G. americana foi a espécie menos injuriada e a que apresentou menor taxa de acúmulo diário de flúor. Entretanto, em $J$. princeps e $P$. dubium, essa relação não foi verificada pois $P$. dubium acumulou quase o dobro do flúor presente nas folhas de J. princeps, apesar de nestas espécies os sintomas terem sido semelhantes. Também no controle, $P$. dubium apresenta maior quantidade de flúor do que $J$. princeps. Desta forma, a quantidade de flúor acumulada nos tecidos e o grau de injúria provocado por esse poluente variam com a espécie e com o estádio de desenvolvimento da planta.

A quantidade de flúor acumulada pelas plantas e a gravidade dos danos provocados por esse poluente dependem, dentre outros fatores, da suscetibilidade geneticamente determinada, de fatores climáticos e edáficos, da interação entre poluentes, da concentração na atmosfera e tempo de exposição e do estádio de desenvolvimento da planta (Treshow \& Anderson 1991). A influência desse último fator, entre as espécies analisadas, foi evidenciada pois as respostas de plântulas e mudas foram diferentes, tanto em relação aos sintomas quanto a quantidade de flúor acumulada.

Apesar de terem sido verificados sinais visíveis de injúria, em G. gorazema e J. princeps não foram observadas alterações no crescimento em altura nas mudas dessas espécies. Por se tratar de espécies florestais arbóreas, é possível que a duração do experimento tenha sido insuficiente para provocar alterações no crescimento de algumas espécies, como verificado para outros poluentes (Dixon \& Kuja 1995).

Arndt et al. (1995) classificaram as plantas de acordo com o grau de resistência ao flúor (sensível, intermediária, moderadamente resistente e resistente) indicando que alguns representantes da família Anacardiaceae apresentam resistência intermediária. No entanto, $S$. dulcis, pertencente à essa família, mostrou grande sensibilidade ao flúor.

O flúor parece acelerar a senescência das folhas, já que, em G. gorazema, foi verificada abscisão das folhas basais, como também relatado por Leece et al. (1986), para Vitis vinifera.

Os sintomas do flúor verificados no presente experimento foram as características necroses marginais e apicais encontradas pela ação do flúor gasoso nas folhas (Garber 1973, Leece et al. 1986). Tais necroses também foram encontradas em outros experimentos conduzidos com flúor dissolvido em água de chuva e as alterações anatômicas observadas em plantas de $S$. dulcis foram semelhantes às descritas para Glycine max e Panicum maximum (Azevedo 1995, Chaves 1997), em resposta ao flúor.

Necroses apicais e marginais simultâneas promoveram o enrugamento de algumas regiões das folhas de $S$. dulcis, ocasionado, provavelmente, pelo efeito mais acentuado do flúor sobre a expansão das células da epiderme adaxial, que recebe diretamente a chuva com flúor. As células do parênquima lacunoso e da epiderme abaxial se expandem, normalmente, originando protuberâncias e depressões na face abaxial do folíolo.

Os dados obtidos sugerem uma grande sensibilidade de $S$. dulcis ao flúor sendo, portanto, um potencial bioindicador da presença desse poluente. Propõem-se estudos mais amplos com essa espécie a fim de possibilitar a diagnose mais precisa da injúria por flúor. 
Agradecimentos - A Germano Leão Demolin Leite e Daniel Melo de Castro, pela colaboração nas análises estatísticas e ao CNPq, pela bolsa concedida à primeira autora.

\section{Referências bibliográficas}

ALVES, P.L.C.A., OLIVA, M.A., CAMBRAIA, J. \& SANT'ANNA, R. 1990. Efeitos da chuva ácida simulada e de um solo de Cubatão (SP) sobre parâmetros relacionados com a fotossíntese e a transpiração de plantas de soja. Revista Brasileira de Fisiologia Vegetal 2:7-14.

ALVES, P.L.C.A. \& OLIVA, M.A. 1993. Reações da soja a chuva ácida e solo contaminado. Ambiente 7:34-39.

ARNDT, U., FLORES, F. \& WEINSTEIN, L. 1995. Efeitos do flúor sobre as plantas: diagnose de danos na vegetação do Brasil. Ed. da Universidade/UFRGS, Porto Alegre.

AZEVEDO, A.A. 1995. Ação do flúor, em chuva simulada, sobre a estrutura foliar de Glycine max (L.) Merril. Tese de doutorado, Universidade de São Paulo, São Paulo.

BERLYN, G.P. \& MIKSCHE, J.P. 1976. Botanical microtechnique and cytochemistry. The Iowa State University Press, Ames.

BUSTAMANTE, M., OLIVA, M.A., SANTA'ANNA, R. \& LOPES, N.F. 1993. Sensibilidade da soja ao flúor. Revista Brasileira de Fisiologia Vegetal 5:151-157.

CASTRO, P.S., RIBEIRO, J.C., RIBEIRO, G.A., SOARES, V.P., BARROS, N.F., GOMES, L.C.L., NEVES, J.C.L., SOUZA, A.L., GALVÃO, D.M. \& VALENTE, O.F. 1987. Estudos preliminares sobre a química da precipitação na região industrial do vale do rio Doce - MG. Convênio SIF/IBDF, Viçosa.

CHAVES, A.L.F. 1997. Ação do flúor dissolvido em chuva simulada sobre a estrutura foliar de Panicum maximum Jacq. (colonião) e Chloris gayana Kunth. (capim-Rhodes) Poaceae. Dissertação de mestrado, Universidade Federal de Viçosa, Viçosa.

DAVISON, A.W. 1983. Uptake, transport and accumulation of soil and airborne fluoride by vegetation. In Fluorides: effects on vegetation, animals and humans (J.L. Shupe, H.B. Peterson \& N.C. Leone, eds.). Paragon Press, Salt Lake City, p.61-82.

DIXON, M.J. \& KUJA, A.L. 1995. Effects of simulated acid rain on the growth, nutrition, foliar pigments and photosynthetic rates of sugar maple and white spruce seedlings. Water, Air and Soil Pollution 83:219-236.

DOBBS, C.G. 1974. Fluoride and the environment. Fluoride 7:123-135.

DOMINGOS, M., KLUMPP, A. \& KLUMPP, G. 1998. Air pollution impact on the Atlantic forest in the Cubatão region, SP, Brazil. Ciência e Cultura 50:230-236.

ELLENBERG, H., ARNDT, U., BRETTHAUER, R., RUTHSATZ, B. \& STEUBING, L. 1991. Biological monitoring: signals from the environment. Vieweg, Berlin.

EVANS, L.S., GMUR, N.F., \& COSTA, F. 1977. Leaf surface and histological perturbations of leaves of Phaseolus vulgaris and Helianthus annuus after exposure to simulated acid rain. American Journal of Botany 64:903-913.

GARBER, K. 1973. The differential diagnosis of fluoride damage to plants. Fluoride 6:33-40.
GARCIA-CIUDAD, A., GARCIA-CRIADO, B. \& EMETRIO, C.P. 1985. Determination of fluoride in plant samples by a potentiometric method and near-infrared reflectance spectroscopy. Communications in Soil Science and Plant Analysis 16:1107-1122.

IEF - Instituto Estadual de Florestas. 1994. Pesquisas prioritárias para o Parque Estadual do Rio Doce, Brasil. Belo Horizonte, p.1-35.

KLUMPP, A., KLUMPP, G. \& DOMINGOS, M. 1994. Plants as bioindicators of air pollution at the Serra do Mar near the industrial complex of Cubatão, Brazil. Environmental Pollution 85:109-116.

KLUMPP, G., KLUMPP, A., DOMINGOS, M. \& GUDERIAN, R. 1995. Hemerocallis as bioindicator of fluoride pollution in tropical countries. Environmental Monitoring and Assessment 35:27-42.

KLUMPP, A., KLUMPP, G. \& DOMINGOS, M. 1996a. Bioindication of air pollution in the tropics. Gefahrstoffe Reinhaltung der Luft 56:27-31.

KLUMPP, A., KLUMPP, G., DOMINGOS, M. \& SILVA, M.D. 1996b. Fluoride impact on native tree species of the Atlantic forest near Cubatão, Brazil. Water, Air and Soil Pollution 87:57-71.

KÖPPEN, W. 1948. Climatologia: com un estudio de los climas de la tierra. Trad. P. R. Hendrichs Pérez. Fondo de Cultura Econômica, Mexico, DF, p.152-182.

KOZLOWSKI, T.T. 1980. Impacts of air pollution on forest ecosystems. BioScience 30:89-93.

KOZLOWSKI, T.T. \& PALLARDY, S.G. 1997. Growth control in woody plants. Academic Press, London.

LARSEN, S. \& WIDDOWSON, A.E. 1971. Soil fluorine. Journal of Soil Science 22:210-221.

LEECE, D.R., SCHELTEMA, J.H. \& ANTTONEN, T. 1986. Fluoride accumulation and toxicity in grapevines Vitis vinifera L. in New South Wales. Environmental Pollution 40:145-172.

MILLER, G.W. 1993. The effect of fluoride on higher plants. Fluoride 26:3-22.

MUDD, J.B. \& KOZLOWSKI, T.T. 1975. Responses of plants to air pollution. Academic Press, New York.

MURRAY, F. 1981. Effects of fluorides on plant communities around an aluminium smelter. Environmental Pollution Series A 24:45-56.

OLIVA, M.A., FIGUEIREDO, J.G. \& SOUZA, M.M. 1997. Bioindicação do flúor mediante gramíneas tropicais. In Indicadores ambientais (H.L. Martos \& N.B. Maia, coords.). PUC/Shell Brasil S.A., Sorocaba, p.191-204.

PRADO FILHO, J.F.P. 1993. Uso de bioindicadores para monitoramento do ar. Ambiente 7:57-64.

SMITH, F.A. \& HODGE, H.C. 1979. Airborne fluorides and man: Part I. CRC Critical Review of Environment Control 8:293-372.

STREHL, T. \& ARNDT, U. 1989. Alterações apresentadas por Tillandsia aeranthos e $T$. recurvata (Bromeliaceae) expostas ao $\mathrm{HF}$ e $\mathrm{SO}_{2}$. Iheringia 39:3-17.

TRESHOW, M. \& ANDERSON, F.K. 1991. Plant stress from air pollution. John Wiley \& Sons, Chichester.

VUONO, Y.S., LOPES, M.I.M.S. \& DOMINGOS, M. 1984. Poluição atmosférica e elementos tóxicos na Reserva Biológica do Instituto de Botânica, São Paulo, Brasil. Revista Brasileira de Botânica 7:149-156.

WEINSTEIN, L.H.1977. Fluoride and plant life. Journal of Occupational Medicine 19:49-78. 